\title{
Rectal Hyposensitivity
}

\author{
Rebecca E Burgell and S Mark Scott*
}

Academic Surgical Unit (GI Physiology Unit), Wingate Institute and Neurogastroenterology Group, Barts and The London School of Medicine and Dentistry, Queen Mary University of London, London, United Kingdom

Impaired or blunted rectal sensation, termed rectal hyposensitivity $(\mathrm{RH})$, which is defined clinically as elevated sensory thresholds to rectal balloon distension, is associated with disorders of hindgut function, characterised primarily by symptoms of constipation and fecal incontinence. However, its role in symptom generation and the pathogenetic mechanisms underlying the sensory dysfunction remain incompletely understood, although there is evidence that RH may be due to 'primary' disruption of the afferent pathway, 'secondary' to abnormal rectal biomechanics, or to both. Nevertheless, correction of RH by various interventions (behavioural, neuromodulation, surgical) is associated with, and may be responsible for, symptomatic improvement. This review provides a contemporary overview of $\mathrm{RH}$, focusing on diagnosis, clinical associations, pathophysiology, and treatment paradigms.

(J Neurogastroenterol Motil 2012;18:373-384)

\section{Key Words}

Constipation; Fecal incontinence; Rectal hyposensitivity

\section{Introduction}

To date, investigation of hindgut dysfunction in patients with functional bowel disorders (primarily manifesting as symptoms of constipation, fecal incontinence, or both) has either focused on the assessment of potential motor (or morphological) abnormalities (transit studies, investigation of anorectal/rectosigmoid contractile activity and tests of evacuatory function etc) or, particularly with regard to the irritable bowel syndrome (IBS), possible alterations in visceral sensation, predominantly hypersensitivity (ie, heightened sensation). ${ }^{1}$ By contrast, the study of blunted or impaired visceral sensation (hyposensitivity) has been relatively neglected. Furthermore, sensory and motor components of the gastrointestinal tract have generally been examined in isolation, leading to a paucity of research examining the complex interplay between afferent and efferent functions. This approach is illogical, as it is clear that intact sensation is fundamental to normal gut functions, and ultimately to normal defecation. ${ }^{2}$

In health, rectal evacuation requires a coordinated series of events that commences with the development of specific pre-defecatory colonic motor activities, ${ }^{2}$ resulting in intermittent filling of the rectum that, in the setting of intact sensation and in the presence of sufficient stool, will trigger the perception of rectal fullness through rectal afferent pathways. This will result in relaxation of the internal anal sphincter as a result of the recto-anal inhibitory reflex, allowing 'sampling' of intraluminal contents ${ }^{2}$ by the more sensitive anal mucosa, enabling discrimination between solid, liquid and gas. Defecation may then occur when socially acceptable. Normal rectal and anal sensory functions are thus es-

Received: July 19, 2012 Revised: September 5, 2012 Accepted: September 13, 2012

(c) This is an Open Access article distributed under the terms of the Creative Commons Attribution Non-Commercial License (http://creativecommons. org/licenses/by-nc/3.0) which permits unrestricted non-commercial use, distribution, and reproduction in any medium, provided the original work is properly cited.

*Correspondence: S Mark Scott, PhD

The Wingate Institute for Neurogastroenterology, 26 Ashfield Street, London E1 2AJ, United Kingdom

Tel: +44-20-7882-3469, Fax: +44-20-7375-2103, E-mail: m.scott@qmul.ac.uk

Financial support: None.

Conflicts of interest: None. 
sential to the process of defecation. ${ }^{2}$ If rectal sensation is impaired, it therefore has the potential to compromise evacuatory function or continence, resulting in definable symptoms and clinical syndromes. Indeed, studies of patients with heightened rectal sensation have found significant association with a number of functional gastrointestinal disorders, ${ }^{3-6}$ with rectal hypersensitivity being proposed as a hallmark of IBS. ${ }^{7}$ Similar work has yet to be realised in patients with rectal hyposensitivity $(\mathrm{RH})$, although it is an area receiving increasing attention.

$\mathrm{RH}$ can be defined as diminished sensation of the rectum to all modalities of stimuli. However, historically, and for the purposes of clinical investigation, it is generally defined as blunted sensation to mechanical balloon distension. RH was first described in 1951 in patients who had undergone parasympathetic block prior to surgery, ${ }^{8}$ and was subsequently noted in patients with anorectal dysfunction secondary to supraconal spinal cord injuries. ${ }^{9,10}$ Later it was clearly recognized in individuals with idiopathic constipation. ${ }^{11,12}$ More recent work has shown that blunted sensation to rectal distension occurs in almost a quarter of adult patients with chronic idiopathic constipation, ${ }^{11-13}$ and in up to two-thirds of idiopathic pediatric constipation. ${ }^{14-16}$ It is also found in $10 \%$ of patients with fecal incontinence. ${ }^{17}$ Despite occurring frequently, and often as the only discernible physiological abnormality, ${ }^{17}$ little is known as to its pathogenesis or true clinical impact. This review will consider contemporary understanding of rectal hyposensitivity, particularly with reference to patients with intractable constipation.

\section{Diagnosis of Rectal Hyposensitivity (See Table)}

Generally, RH is detected clinically when sensory thresholds to simple balloon distension with a hand-held syringe are elevated beyond the normal ranges. ${ }^{18}$ More exacting measurements can be made with a computer-controlled barostat, which has the added advantage of providing information as to the biomechanical properties of the gut wall, as well as examining sensory perception. The barostat is considered the gold-standard for assessment of sensory function. ${ }^{19}$ There are 2 main techniques utilized: (1) sensory thresholds and (2) stimulus intensity assessments. A sensory threshold protocol involves gradual distension of the bowel with an infinitely compliant balloon using stepwise increases in pressure with time. The subject is asked to note when the first constant sensation, urge threshold and maximal tolerable intensity are reached, with hyposensitivity diagnosed as elevated pressure/volumes in comparison to the normal population. ${ }^{18,20}$ By contrast, the stimulus intensity technique involves distension of the rectum to a random program of set pressures, with the subject asked to rate intensity experienced using a visual analog scale, ${ }^{19,21,22}$ In this setting, hyposensitivity is diagnosed when the subject reports visual analog scale values below that of the normal range. $^{18}$

Electrical stimulation of the rectum can also be used as a sensory stimulus to assess visceral afferent function. ${ }^{23-25}$ While electrical stimulation is less physiological, it bypasses mucosal receptors and activates the nerve directly, thus avoiding confounding influences of bowel wall properties, while providing a precise reproducible stimulus. Furthermore, it can be used to produce a cortical evoked potential, providing an objective measurement of the afferent nerve pathway supplying the bowel. ${ }^{26}$ Technology also exists to measure the sensitivity to noxious thermal stimuli. ${ }^{27,28}$ This is an important modality as, in contrast to electrical stimulation, it relies on intact receptor function. This is currently only used for research purposes. ${ }^{27}$ As with mechanical distension, $\mathrm{RH}$

Table. Comparison of Techniques Used for the Diagnosis of Rectal Sensory Dysfunction

\begin{tabular}{|c|c|c|}
\hline Test & Advantages & Disadvantages \\
\hline $\begin{array}{l}\text { Latex balloon distension } \\
\text { (clinical use) }\end{array}$ & $\begin{array}{l}\text { Cheap and quick } \\
\text { Reproducible }\end{array}$ & $\begin{array}{l}\text { Intrinsic elastic properties of the balloon limit } \\
\text { assessment of rectal wall properties } \\
\text { Axial extension into sigmoid during distension possible }\end{array}$ \\
\hline $\begin{array}{l}\text { Barostat distension } \\
\text { (clinical use) }\end{array}$ & $\begin{array}{l}\text { Provides additional information on bowel wall } \\
\text { biomechanical properties } \\
\text { Conforms to the outline of the visceral organ under study }\end{array}$ & $\begin{array}{l}\text { More prolonged study required } \\
\text { Considerably more expensive than latex balloon }\end{array}$ \\
\hline $\begin{array}{l}\text { Electrical stimulation } \\
\text { (predominantly research use) }\end{array}$ & $\begin{array}{l}\text { Highly reproducible, precise stimulus } \\
\text { Problematic if rectal wall apposition is poor }\end{array}$ & $\begin{array}{l}\text { Non physiological } \\
\text { Bypasses mucosal receptors }\end{array}$ \\
\hline $\begin{array}{l}\text { Thermal stimulation } \\
\text { (research only) }\end{array}$ & $\begin{array}{l}\text { Highly reproducible, precise stimuli } \\
\text { Requires intact mucosal receptors }\end{array}$ & $\begin{array}{l}\text { Non physiological } \\
\text { Clinical utility not established }\end{array}$ \\
\hline
\end{tabular}


to either electrical or thermal stimulation is diagnosed when recorded thresholds are elevated beyond the normal range.

\section{Summary}

- $\mathrm{RH}$ is generally diagnosed clinically when sensory thresholds to simple volumetric balloon distension with a hand-held syringe are elevated.

- The gold standard for diagnosis of RH is using a computer controlled barostat.

- In the research setting, electrical and thermal sensitivity have also been used to examine specific elements of sensory function.

\section{Prevalence and Associated Conditions}

$\mathrm{RH}$ has been found in up to $67 \%$ of patients with complete spinal cord injury and hindgut dysfunction, and in $6 \%$ of individuals with incomplete lesions. ${ }^{10,29}$ Studies have also shown that patients with multiple sclerosis and diabetes have higher rectal sensory thresholds ${ }^{30-32}$ than healthy individuals. In the absence of confirmed neurological dysfunction, $\mathrm{RH}$ is present in $23 \%$ of adult patients with constipation, $10 \%$ of patients with fecal incontinence (FI) and $27 \%$ of patients in whom these symptoms co-existent $^{17}$; nevertheless, up to $63 \%$ of such individuals give a history that includes factors that could potentially disrupt the afferent pathway, ${ }^{33}$ suggesting this may be the primary pathogenic mechanism. By way of example, in the largest published series of patients with $\mathrm{RH}$ to date, $38 \%$ had undergone prior pelvic surgery, $22 \%$ anal surgery and $13 \%$ described prior spinal trauma. ${ }^{33}$ Approximately $30 \%$ of patients attributed the onset of their symptoms to these events. In addition, $\mathrm{RH}$ is found in up to $17 \%$ of patients with the IBS, ${ }^{34}$ most commonly in those with constipation predominance who have lost the call to stool ('no urge' constipation). ${ }^{35}$ Patients with hyposensitivity and IBS are also more likely to have obvious abdominal distension in association with the symptom of bloating, ${ }^{36}$ whereas patients with normal or hypersensitivity report bloating in the absence of distension.

In patients with symptoms of evacuatory dysfunction, $\mathrm{RH}$ is more common in individuals with 'functional' obstructive features on proctography (eg, dyssynergic defecation; poor defecatory dynamics), rather than those with obstructive structural phenomena, ${ }^{37,38}$ with recent studies showing that RH is not associated with mechanical obstruction as a result of either rectocoele ${ }^{39}$ or intussusceptions. ${ }^{38}$ In adult incontinent patients, $\mathrm{RH}$ is more frequently seen in conjunction with functional sphincter abnormalities (ie, incompetent, but structurally intact) and also increased prevalence of constipation symptoms, ${ }^{37}$ suggesting that the incontinence may be a secondary phenomenon (as clearly recognised in both pediatric and geriatric populations). Incontinent patients with $\mathrm{RH}$ are also more likely to have impaired evacuation (ie, prolonged defecation or incomplete rectal emptying on proctography $^{37}$ ). In pediatric patients, two-thirds of those with fecal retentive disorders have abnormal sensation thresholds on volumetric studies, ${ }^{15}$ although more detailed barostat studies indicate that this is predominantly related to rectal wall biomechanical abnormalities such as megarectum or hypercompliance of the rectal wall. ${ }^{40}$

Clinically, it is also often noted anecdotally that patients with RH describe an attenuated, altered or absent call to stool. ${ }^{35,41}$ Such patients more frequently describe lower abdominal pain or cramping as the stimulus for defecation in contrast to those with normal sensation, who appear to associate the call to stool with a sensation of rectal or suprapubic fullness. In a recent study, ${ }^{42}$ where 50 patients with constipation and 21 healthy control subjects were asked to verbally describe their call to stool, and also pictorially represent the anatomical site of desire to defecate, $13 \%$ of patients reported a loss or absence of the call to stool vs only $3 \%$ of healthy controls $(P=0.015)$; in $87 \%$ of patients, the quality of sensation was volunteered using more varied descriptors than in health $(P<0.01)$; and there was a wider area of viscerosomatic referral in patients $(P<0.001)$.

\section{Summary}

- $\mathrm{RH}$ is found most commonly in patients with spinal cord injury or clinically documented neuropathy; however it is also seen in patients without overt neurological compromise.

- $\mathrm{RH}$ is found in up to $23 \%$ of patients with constipation.

- $\mathrm{RH}$ is more common in patients with functional (ie, dyssynergic defecation) rather than structural (ie, rectocoele and intussusception) causes for their defecatory difficulties.

- Ten percent of patients with incontinence also have RH.

\section{Pathophysiology}

\section{Rectal Innervation}

The innervation of the rectum is more complex than that of the colon, as it is supplied by visceral afferents as well as somatic nerves arising from the pudendal nerve. This dual innervation 
appears confined to the lower third of the rectum $(<7 \mathrm{~cm}$ from anal verge), as a pudendal nerve block has no effect on sensation to distension or thermal stimuli in the mid and upper rectum. ${ }^{43}$

The afferent component of the so called "brain-gut axis" involves visceral afferents of the enteric nervous system, ${ }^{44}$ which are thought to be both chemosensitive and mechanosensitive and end as bare nerve fibers in the myenteric plexus within the gut wall. ${ }^{45}$ They are generally unmyelinated $\mathrm{C}$ fibers, although some $\mathrm{A} \delta$ fibers are seen. ${ }^{46}$ The enteric neurons communicate via interneurons with extrinsic sacral afferents, usually seen associated with blood vessels in the mesentery or serosa, but also extending further into the myenteric plexus or muscle layers. ${ }^{45}$ Enteric afferents also directly communicate with enteric motor neurons to effect local reflexes. ${ }^{44}$ The extrinsic spinal sensory fibers follow the path of the somatic and efferent autonomic nerves ${ }^{47}$ to the spine, with cell bodies in the sacral dorsal root ganglia (S1-S2). ${ }^{44}$ These then synapse with second order neurons in the spinothalamic and spinoreticular tracts of the spinal cord, ultimately projecting to the thalamus where they are relayed to higher centres (Figure). ${ }^{45,47}$ Cortical perception of sensation is a critical component of the sensory pathway, as psychological profile and psychopathology have been shown to correlate with the response to visceral distension. ${ }^{48-50}$ Theoretically, disruption of the afferent pathway from the rectum, at any level from receptor to cortex, could potentially

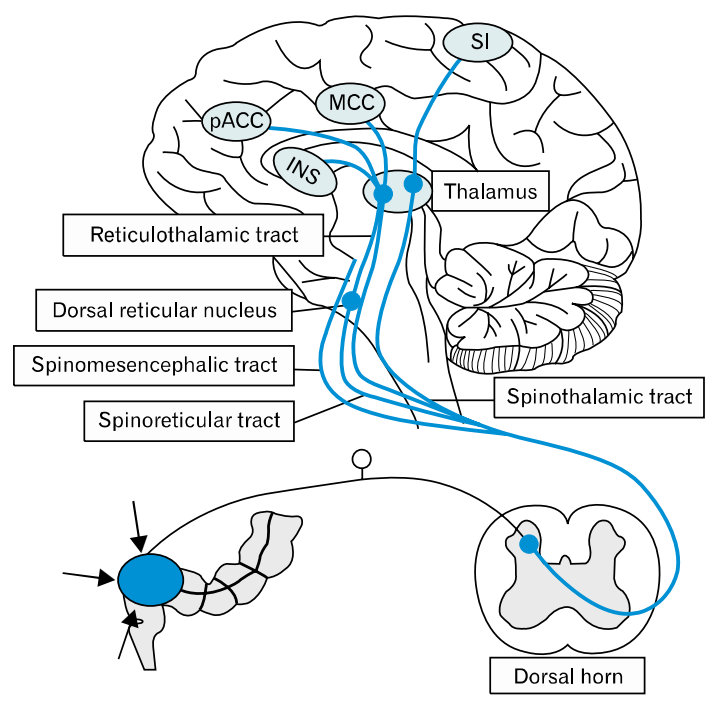

Figure. Sensory pathways from the rectum to the higher cortical centers (reproduced from Sharma et al with permission: Sharma A, Lelic D, Brock C, Paine P, Aziz Q. New technologies to investigate the brain gut axis. World J Gastroenterol 2009;15:182-191). pACC, perigenual anterior cingulate cortex; MCC, mid cingulate cortex; INS, insular; SI, somatosensory cortex. Arrows indicate visceral distension. lead to impaired perception of rectal stimuli.

\section{Pathophysiology of Rectal Hyposensitivity}

Although RH is generally diagnosed on the basis of elevation of sensory thresholds to rectal distension, recent studies involving complementary modalities (barostat, electrical and thermal stimulation, and fluoroscopic screening during distension studies $^{13,21,51}$ ) have allowed subdivision of RH into "primary" RH (thought due to direct disruption/dysfunction of the afferent pathway); "secondary" RH (proposed to be due to altered rectal biomechanical properties, such as an enlarged [mega] rectum, or increased compliance/stretch of the rectal wall, thus requiring elevated distension volumes to induce the same sensory stimulus); or both. Primary RH is elevation of thresholds to all modalities of stimulation in the presence of normal rectal biomechanical properties. In the largest series of patients with $\mathrm{RH}$ to have undergone comprehensive physiological assessment, one-third were found to have primary RH, $42 \%$ secondary $\mathrm{RH}$, and $25 \%$ had both. ${ }^{13}$ Unfortunately, the majority of other studies to date have not made such a distinction between groups. The ability to accurately phenotype such patients is becoming increasingly relevant, as new pharmaceutical and surgical treatments become available, the effectiveness of which may well depend on accurate diagnosis.

In patients in whom there is documented disruption of the afferent pathway (eg, due to pelvic nerve damage or spinal cord injury), the cause-effect relationship to the development of RH appears clear cut. However the role that sub-clinical systemic neuronal dysfunction plays in the development of $\mathrm{RH}$ is less clear. Landmark studies in patients with FI suggest that $\mathrm{RH}$ and sphincter dysfunction is a marker for occult spinal cord injury (with up to $10 \%$ of patients affected), ${ }^{52,53}$ and in another study, up to $30 \%$ of patients with constipation were found to have incidental lower spinal dysraphism ${ }^{12}$ (unfortunately, rectal sensory status was unknown). Damage to the pelvic nerves either during childbirth, ${ }^{54}$ due to chronic straining at stool, ${ }^{55}$ or due to pelvic surgery (particularly hysterectomy) has also been postulated as a cause. ${ }^{33,56}$ Nevertheless, the level at which neuronal pathway dysfunction occurs in individuals with $\mathrm{RH}$ remains to be elucidated. Interestingly, such patients appear to have intact spinal reflexes. When the recto-anal inhibitory reflex, rectoanal contractile response and sensorimotor response are tested, although patients with $\mathrm{RH}$ require higher volumes of rectal distension to induce reflexive responses than healthy individuals, those reflexes are preserved. ${ }^{57}$ This suggests any potential abnormality may be above the level of the reflex arc. Furthermore, early evidence 
(from studies of esophageal pain and in patients with IBS) suggests that visceral sensory function may also be influenced by personality profile, autonomic nervous system function and psychological phenotype $;^{58-62}$ however this has yet to be examined directly in patients with rectal hyposensitivity.

A recent study in 11 healthy volunteers and 13 patients with constipation and $\mathrm{RH}$ looked at the location of the proposed afferent pathway defect in more detail. ${ }^{63}$ Using evoked potential recording and inverse modeling techniques of cortical dipoles, a temporal delay in afferent transmission in patients in comparison to volunteers was found $(142 \pm 24$ vs $116 \pm 15 \mathrm{~ms} ; P=0.004)$, although there was no difference in the location of cortical processing. Rectal electrical stimulation (as used to induce the evoked potential) is known to bypass end-organ receptors and directly stimulate the surrounding neuronal axons, and therefore any changes seen in evoked potential latencies are not an effect simply of aberrant receptor function. This suggests that the defect may lie within the spinal cord or peripheral nerves. This is important clinically, as, unlike patients with IBS, who have been shown to have altered cortical processing on inverse modeling studies, ${ }^{64,65}$ RH patients may be less likely to benefit from psychoemotional therapy designed to influence cortical function.

Constipated patients have also been shown to have altered autonomic function, ${ }^{66,67}$ small sensory fiber dysfunction ${ }^{68,69}$ and also anal sensory hyposensitivity. ${ }^{70}$ Unfortunately such studies were not stratified by rectal sensory status, with one notable exception by Vasudevan et al, ${ }^{70}$ who examined anal sensation and found that although anal hyposensitivity is associated with constipation per se, it is not associated with the presence of $\mathrm{RH}$, suggesting that different etiopathological processes are involved in the impairment of anal sensation (somatic) and rectal (visceral) sensation. ${ }^{70}$ It is thus unclear whether the sensory abnormalities seen in $\mathrm{RH}$ are an isolated visceral phenomenon or simply a feature of a more generalized neuropathic disorder.

The influences that altered central processing/descending inhibition or psychological profile have on the presence of $\mathrm{RH}$ are also unclear. A small number of studies in patients with inflammatory bowel disease have found that although during periods of active inflammation there is rectal hypersensitivity, ${ }^{71,72}$ during quiescence rectal sensory thresholds are increased. ${ }^{73}$ This has been postulated to be due to descending inhibition of sacral dorsal horn neurons in response to chronic inflammation. ${ }^{73,74}$ Furthermore, a number of studies have shown that experimental stress is associated with changes in visceral sensitivity (generally towards the development of hypersensitivity ${ }^{75-77}$ ), although such studies have not been focused to RH. There is also evidence that a past history of trauma such as sexual abuse appears to be associated with the presence of elevated sensory thresholds to distension. $^{78,79}$

Other work in animal models suggests that the luminal contents of the bowel can influence rectal sensitivity; one such study showed that mice developed $\mathrm{RH}$ after undergoing colonic infusion of fecal supernatants from patients with inflammatory bowel disease. By way of contrast, mice who received infusion from patients with the IBS developed hypersensitivity. This response appears to be mediated by protease-activated receptors (PARs), particularly the antinociceptive PAR-4 and PAR-2. ${ }^{80}$

\section{Summary}

- RH may be sub-categorized into primary RH thought to be due to direct disruption/dysfunction of the afferent pathway or secondary, due to altered rectal biomechanical properties (ie, megarectum or increased rectal wall compliance), or both.

- Rectal evoked potential studies indicate altered transmission of afferent information in patients with $\mathrm{RH}$.

- The level at which afferent neuronal dysfunction occurs is yet to be confirmed.

- It is not clear whether the sensory abnormalities seen in $\mathrm{RH}$ are an isolated visceral phenomenon or a feature of a generalized neuropathic disorder.

\section{Role of Rectal Hyposensitivity in the Development of Hindgut Dysfunction}

Ultimately, whether RH contributes to, or is instead a manifestation of hindgut dysfunction (ie, is simply an epiphenomenon) is not clear.

\section{Constipation}

It is hypothesized that $\mathrm{RH}$ leads to constipation via a number of mechanisms. Firstly, hyposensitivity either secondary to rectal wall biomechanical dysfunction or to true afferent dysfunction, may lead to fecal retention and impaction (and likely further dilation of the rectum), due to failure of the development of an urge to defecate. With time, the fecal matter desiccates producing a large hard stool, which is painful and difficult to pass. Secondarily, $\mathrm{RH}$ may underscore rectal evacuatory dysfunction (RED) in a significant proportion of patients. A number of studies ${ }^{17,33,37}$ have now shown RH to be associated with a 'functional' RED, 
manifest as abnormal defecatory dynamics in up to $32 \%,{ }^{33}$ most commonly poor expulsive effort, failure of the anal canal to relax, or development of a hyperacute anorectal angle with straining (ie, pelvic floor dyssynergia), ${ }^{81}$ all of which result in inadequate rectal emptying. This indicates that intact sensation is critical to appropriate recto-anal and pelvic floor co-ordination. ${ }^{56}$ Furthermore, patients with $\mathrm{RH}$ have reduced rectal wall contractility (ie, coincident or corresponding efferent dysfunction) in response to distension, which likely contributes to evacuatory failure. ${ }^{82}$ Thirdly, RH may lead to the development of constipation by influencing colonic motility. Delayed colonic transit, which is an indirect measure of colonic contractile functions, ${ }^{83}$ is found in up to one-third of patients with $\mathrm{RH}^{33}$ Although this delay may reflect a true primary colonic dysmotility, it may alternately be secondary to rectal stasis as a consequence of RH (ie, due to inhibitory feedback mechanisms). ${ }^{84-86}$

\section{Incontinence}

Generally, RH is thought to contribute to the development of FI via its association with functional constipation. ${ }^{87,88}$ Indeed, $\mathrm{RH}$ is most commonly found in patients with coexistent constipation and incontinence, where the latter is predominantly passive in nature ${ }^{17}$; this suggests the fecal leakage is secondary to fecal impaction or impaired evacuation. ${ }^{87}$ An inability to adequately empty the rectum may result in liquid feces or mucus seeping around an impacted bolus of intrarectal stool (otherwise termed "overflow"). ${ }^{89}$ The cause of impaction may be secondary to pelvic floor dysfunction ${ }^{90}$ or inadequate attention to the urge to defecate. Even in the absence of rectal impaction, RH may contribute to the development of FI via impairment of the reflexive or conscious contraction of the anal sphincters; patients with RH have reflexive relaxation of the internal anal sphincter at volumes lower than that required to induce rectal sensation, ${ }^{91,92}$ and thus conscious deferral of defecation may not be possible. ${ }^{87}$ They are also likely to have a functional sphincter defects (ie, reduced manometric pressures in the absence of structural sphincter damage) and pelvic floor dyssynergia. ${ }^{33,37}$ Finally, RH may contribute to FI through its association with pelvic floor weakness and sphincter incompetence, perhaps related to pelvic nerve damage (see above). ${ }^{87}$

\section{Summary}

- RH may lead to constipation via:

(1) Development of fecal retention due to lack of urge

(2) Its association with a functional RED
(3) Influencing colonic motility though inhibitory feedback mechanisms triggered as a result of rectal stasis.

- RH may lead to incontinence via:

(1) Its association with functional constipation, where fecal leakage is secondary to fecal impaction or impaired evacuation, ie, "fecal overflow"

(2) Impairment of the reflexive or conscious contraction of the anal sphincters

(3) An association with pelvic floor weakness.

\section{Treatment Options}

Currently there is no definitive treatment for functional bowel disorders (particularly constipation) associated with rectal hyposensitivity. This is in part because the true clinical role has yet to be substantiated. Several studies have shown, however, that correction of sensory impairment is associated with an improvement in bowel symptoms. ${ }^{93-96}$

\section{Bowel Retraining Therapy/Biofeedback}

Bowel retraining therapy, often incorporating sensory biofeedback is frequently used for the management of constipation and RED. ${ }^{56,85,97,98}$ Enhancement of sensory perception is one of the primary aims of therapy. ${ }^{98}$ However, evidence of targeted therapy to RH is lacking, with no randomized controlled trials available, ${ }^{84,96,97,99}$ and only limited patient numbers (largest study $[\mathrm{n}=26]^{96}$ ). The basis of sensory re-training involves inflating a balloon or barostat in the rectum until urge threshold is reached. With repeated inflations, the patient learns to associate a given sensory intensity with the inflated volume. Over time, the balloon is inflated with decreasing volumes and the patient is asked to closely monitor and attend to sensations experienced. Eventually, new sensory thresholds may be established. Biofeedback has been shown to both objectively (up to $92 \%$ of patients show a significant improvement in sensory thresholds following treatment ${ }^{96,97,99}$ ) and subjectively improve symptoms of constipa$\operatorname{tion}^{84,96,97}$ and incontinence, ${ }^{99,100}$ with sustained improvement for at least 12 months. ${ }^{101}$

\section{Medical Therapy}

Unlike rectal hypersensitivity, where a number of medications aimed at correcting sensory dysfunction ${ }^{102-106}$ have been trialled, there is currently no established medical therapy for treating visceral hyposensitivity. 


\section{Neuromodulation}

Neuromodulation therapy involves modulation of the extrinsic neural control of the pelvic floor via continuous low amplitude stimulation of the sacral nerve roots or via direct stimulation of the organ of interest (ie, anal canal). Currently, neuromodulation research has focussed on end-organ outcomes and hence little is understood as to the true physiological mechanism of action, ${ }^{107}$ although one plausible hypothesis is that its effects are mediated predominantly via changes in afferent neuronal function. ${ }^{108} \mathrm{~A}$ number of different methods and techniques of neuromodulation exist; however, it is possible that the mechanism of action is common to all.

\section{Sacral nerve stimulation}

Sacral nerve stimulation (SNS) involves the placement of stimulating electrodes alongside the $\mathrm{S} 3$ sacral nerve; these are then attached to an implantable stimulator. Whilst neuromodulation with SNS has been shown to be effective in patients with fecal incontinence, ${ }^{107,109,110}$ its role in the treatment of constipation remains controversial, ${ }^{111}$ although promising. ${ }^{111,112}$ Only one small mechanistic study has examined the effects of SNS with particular reference to $\mathrm{RH}$ and constipation, ${ }^{113}$ this found normalization of rectal sensory thresholds with treatment, associated with both an increase in the number of successful bowel actions, and also improved constipation symptom scores. ${ }^{113}$ This suggests a possible mechanistic effect of RH. Larger studies of SNS in constipation have also shown changes in sensory function, with a reduction in urge and maximal tolerable thresholds. ${ }^{112}$ Unfortunately, the majority of studies performed have examined absolute change in rectal sensation (ie, both hyposensitive and hypersensitive patients have been analysed together), rather than by stratifying patients on the basis of sensory status. ${ }^{114-118}$

\section{Electrical stimulation}

Less invasive electrical stimulation techniques than SNS have also been used in the treatment of constipation and are likewise found to influence rectal sensory status. ${ }^{119,120}$ Anal canal electrical stimulation has been shown to be associated with an improvement in both symptoms of constipation as well as a reduction in rectal sensory thresholds, ${ }^{120}$ although its use has yet been generally accepted. More recently, transcutaneous abdominal electrical stimulation and dorsal genital nerve stimulation have been trialed in children and adults respectively, with an improvement in constipation symptoms and rectal perception again shown. ${ }^{121,122}$ The latter study ${ }^{122}$ found this was coincident with a reduction in rectal diameter.

\section{Magnetic stimulation of the lumbosacral nerves}

There is also emerging evidence that extracorporeal lumbosacral magnetic stimulation is effective in treating patients with hindgut dysfunction. ${ }^{94,123,124}$ Magnetic stimulation has been shown to decrease colonic transit times, ${ }^{124}$ decrease rectal sensory threshold volumes, and increase anal pressures ${ }^{125}$ in healthy controls, patients with neuropathic hindgut dysfunction and patients with slow colonic transit. ${ }^{94}$ This is associated with a decrease in constipation symptom scores, ${ }^{124}$ an increase in frequency of defecation, and decreased laxative use. ${ }^{94}$ There appears to be symptomatic benefit for at least 3 months, ${ }^{123,124}$ but no longer term studies have been performed to date. In one important study, symptomatic benefit was associated with a significant decrease in rectal sensory volumes to urge to defecate and maximal toleration. ${ }^{94}$ The responders, as a group, also had significantly higher baseline sensory thresholds (maximal tolerable volume $296 \mathrm{~mL}$ vs 143 $\mathrm{mL})^{94}$ in comparison to the non-responders, suggesting one mechanism of action is via alteration of afferent function.

\section{Surgery}

In highly selected patients with $\mathrm{RH}$ secondary to increased rectal compliance/dimensions (particularly idiopathic megarectum), surgery may be a therapeutic option. A number of surgical procedures exist, and this is reviewed elsewhere. ${ }^{126}$ The majority of procedures involve resection of the rectum and/or sigmoid colon, with either coloanal anastomosis or fecal diversion via colostomy. Although effective ( $\sim 70 \%-80 \%$ success rate, depending of type of procedure), ${ }^{126}$ surgery is generally considered a last resort due to its invasive, frequently irreversible nature and high morbidity $(6 \%-50 \%) .{ }^{127}$ One particular operative technique called vertical reduction rectoplasty, ${ }^{95}$ which was specifically designed to correct rectal biomechanical abnormalities, has been shown to have clinical benefit and sustained physiological (diameter, compliance and sensory function) improvement in at least the medium term (60 months). ${ }^{128}$

\section{Summary}

- There is currently no definitive treatment targeted to RH in functional bowel disorders.

- However, bowel retraining therapy incorporating sensory biofeedback has been shown to result in a reduction in rectal sensory thresholds to balloon distension. This is associated with a subjective improvement in symptoms.

- There is some evidence that neuromodulation techniques, such as with SNS or extracorporeal magnetic/electrical 
stimulation may be an effective treatment for patients with functional bowel disorders associated with RH.

- Surgery can be considered in highly selected patients where $\mathrm{RH}$ is secondary to increased rectal dimensions.

\section{Clinical Research Implications}

The underlying cause for the finding of $\mathrm{RH}$ has not been unequivocally established, but is almost certainly multifactorial, involving neuroanatomical, psychological and biomechanical factors. In particular, the site or the extent of any disruption to the afferent nerve pathway has not been accurately defined. Likewise, the pathology leading to rectal wall biomechanical changes has yet to be determined. It therefore remains unclear whether RH is itself causative or indeed secondary to hindgut dysfunction, ie, does a true cause and effect relationship exist, or is $\mathrm{RH}$ simply an epiphenomenon. There is growing evidence that constipation starting in childhood (associated with altered sensory thresholds) may persist into adulthood, with $40 \%-50 \%{ }^{129,130}$ of paediatric patients not responding to treatment on long-term follow-up. The relationship between childhood-onset constipation and constipation associated with $\mathrm{RH}$ and biomechanical dysfunction in adulthood certainly warrants further research.

Furthermore, it is not known whether any afferent pathway defect represents an isolated visceral sensory neuropathic process, or reflects a more generalized neuropathy also affecting efferent and/or autonomic function. Although previous work has demonstrated concurrent systemic small fiber sensory dysfunction and autonomic dysfunction in patients with constipation, ${ }^{66,69}$ the relationship to rectal sensory status was not documented. Such a study is currently underway.

Most importantly, the clinical impact of the presence of $\mathrm{RH}$ needs to be fully appreciated. Akin to the association between visceral hypersensitvity and the IBS, an association between $\mathrm{RH}$ and RED has been firmly established, ${ }^{33}$ and there certainly appears to be a strong link between $\mathrm{RH}$ and an altered 'call to stool, ${ }^{35,41,42}$ and also an effect on other physiological functions (eg, colonic transit ${ }^{33}$ and rectal evacuation ${ }^{17}$ ). However, whether correction of $\mathrm{RH}$ is the responsible mechanism for concurrent symptomatic improvement seen with a number of different interventions $^{84,94,96,97,99,113,120}$ remains unclear, though results to date appear promising. Further controlled studies with larger numbers are an absolute requirement to substantiate this.

\section{Summary}

- The underlying causes (be that neurological or biomechanical) for RH need to be unequivocally established.

- It remains to be confirmed whether RH is causative or, alternatively, is secondary (ie, an epiphenomenon) to hindgut dysfunction.

- The clinical impact of RH still needs to be better defined.

\section{Conclusion}

$\mathrm{RH}$ is commonly found in patients with hindgut dysfunction, and is often the only pathophysiological abnormality identified in these individuals. In terms of etiopathogenesis, it can be subdivided into two main groups (of which there is likely considerable overlap), namely primary afferent nerve dysfunction or secondary to biomechanical changes of the rectal wall. However the mechanism by which it exerts its effects in relation to symptom generation remains to be fully elucidated. Furthermore, whether there is a clear clinical phenotype associated with the finding of RH has still to be confirmed. Nevertheless, normalization of $\mathrm{RH}$ has been shown through a variety of interventions (behavioral, neuromodulation and surgery) to be associated with clinical benefit. Ultimately, appreciation of the mechanisms responsible for RH has potentially important and wide-ranging implications for the management of functional hindgut disorders, as new and evolving therapies targeted to correcting sensory function become available.

\section{References}

1. Azpiroz F, Bouin M, Camilleri M, et al. Mechanisms of hypersensitivity in IBS and functional disorders. Neurogastroenterol Motil 2007;19:62-88

2. Palit S, Lunniss PJ, Scott SM. The physiology of human defecation. Dig Dis Sci 2012;57:1445-1464.

3. Mertz H, Naliboff B, Munakata J, Niazi N, Mayer EA. Altered rectal perception is a biological marker of patients with irritable bowel syndrome. Gastroenterology 1995;109:40-52.

4. Poitras P, Riberdy Poitras M, Plourde V, Boivin M, Verrier P. Evolution of visceral sensitivity in patients with irritable bowel syndrome. Dig Dis Sci 2002;47:914-920.

5. Farmer AD, Aziz Q. Visceral pain hypersensitivity in functional gastrointestinal disorders. Br Med Bull 2009;91:123-136.

6. Camilleri M. Testing the sensitivity hypothesis in practice: tools and methods, assumptions and pitfalls. Gut 2002;51(suppl 1):i34i40.

7. Mertz H. Review article: visceral hypersensitivity. Aliment Pharmacol Ther 2003;17:623-633. 
8. Goligher JC, Hughes ES. Sensibility of the rectum and colon. Its role in the mechanism of anal continence. Lancet 1951;1:543-547.

9. MacDonagh R, Sun WM, Thomas DG, Smallwood R, Read NW. Anorectal function in patients with complete supraconal spinal cord lesions. Gut 1992;33:1532-1538.

10. Greving I, Tegenthoff M, Nedjat $\mathrm{S}$, et al. Anorectal functions in patients with spinal cord injury. Neurogastroenterol Motil 1998; 10:509-515.

11. Shouler P, Keighley MR. Changes in colorectal function in severe idiopathic chronic constipation. Gastroenterology 1986;90:414420.

12. Varma JS, Smith AN. Neurophysiological dysfunction in young women with intractable constipation. Gut 1988;29:963-968.

13. Gladman MA, Aziz Q, Scott SM, Williams NS, Lunniss PJ. Rectal hyposensitivity: pathophysiological mechanisms. Neurogastroenterol Motil 2009;21:508-516. e4-e5.

14. van den Berg MM, Voskuijl WP, Boeckxstaens GE, Benninga MA. Rectal compliance and rectal sensation in constipated adolescents, recovered adolescents and healthy volunteers. Gut 2008;57: 599-603.

15. Meunier P, Marechal JM, de Beaujeu MJ. Rectoanal pressures and rectal sensitivity studies in chronic childhood constipation. Gastroenterology 1979;77:330-336.

16. van den Berg MM, Di Lorenzo C, van Ginkel R, Mousa HM, Benninga MA. Barostat testing in children with functional gastrointestinal disorders. Curr Gastroenterol Rep 2006;8:224-229.

17. Gladman MA, Scott SM, Chan CL, Williams NS, Lunniss PJ. Rectal hyposensitivity: prevalence and clinical impact in patients with intractable constipation and fecal incontinence. Dis Colon Rectum 2003;46:238-246.

18. Scott SM, Gladman MA. Manometric sensorimotor and neurophysiological evaluation of anorectal function. Gastroenterol Clin North Am 2008;37:511-538. vii.

19. Whitehead WE, Delvaux M. Standardization of barostat procedures for testing smooth muscle tone and sensory thresholds in the gastrointestinal tract. The Working Team of Glaxo-Wellcome Research, UK. Dig Dis Sci 1997;42:223-241.

20. Cremonini F, Houghton LA, Camilleri M, et al. Barostat testing of rectal sensation and compliance in humans: comparison of results across two centres and overall reproducibility. Neurogastroenterol Motil 2005;17:810-820.

21. Gladman MA, Dvorkin LS, Lunniss PJ, Williams NS, Scott SM. Rectal hyposensitivity: a disorder of the rectal wall or the afferent pathway? An assessment using the barostat. Am J Gastroenterology 2005;100:106-114.

22. Steens J, van der Schaar PJ, Penning C, Brussee J, Masclee AA. Compliance, tone and sensitivity of the rectum in different subtypes of irritable bowel syndrome. Neurogastroenterol Motil 2002;14: 241-247.

23. Loening-Baucke V, Read NW, Yamada T. Further evaluation of the afferent nervous pathways from the rectum. Am J Physiol 1992; 262(5 Pt 1):G927-G933.

24. Loening-Baucke V, Read NW, Yamada T. Cerebral evoked potentials after rectal stimulation. Electroencephalogr Clin Neurophysiol 1991;80:490-495.

25. Speakman CT, Kamm MA, Swash M. Rectal sensory evoked po- tentials: an assessment of their clinical value. Int J Colorectal Dis 1993;8:23-28.

26. Hobday DI, Hobson AR, Sarkar S, Furlong PL, Thompson DG, Aziz Q. Cortical processing of human gut sensation: an evoked potential study. Am J Physiol 2002;283:G335-G339.

27. Chan CL, Scott SM, Birch MJ, Knowles CH, Williams NS, Lunniss PJ. Rectal heat thresholds: a novel test of the sensory afferent pathway. Dis Colon Rectum 2003;46:590-595.

28. Brock C, Nissen TD, Gravesen FH, et al. Multimodal sensory testing of the rectum and rectosigmoid: development and reproducibility of a new method. Neurogastroenterol Motil 2008;20:908918.

29. Pannek J, Greving I, Tegenthoff M, et al. Urodynamic and rectomanometric findings in patients with spinal cord injury. Neurourol Urodyn 2001;20:95-103.

30. Caruana BJ, Wald A, Hinds JP, Eidelman BH. Anorectal sensory and motor function in neurogenic fecal incontinence. Comparison between multiple sclerosis and diabetes mellitus. Gastroenterology 1991;100:465-470.

31. Nordenbo AM, Andersen JR, Andersen JT. Disturbances of ano-rectal function in multiple sclerosis. J Neurol 1996;243:445451.

32. Bassotti G, Chiarioni G, Vantini I, et al. Anorectal manometric abnormalities and colonic propulsive impairment in patients with severe chronic idiopathic constipation. Dig Dis Sci 1994;39:15581564.

33. Gladman MA, Scott SM, Williams NS, Lunniss PJ. Clinical and physiological findings, and possible aetiological factors of rectal hyposensitivity. Br J Surg 2003;90:860-866.

34. Camilleri M, McKinzie S, Busciglio I, et al. Prospective study of motor, sensory, psychologic, and autonomic functions in patients with irritable bowel syndrome. Clin Gastroenterol Hepatol 2008;6: 772-781.

35. Harraf F, Schmulson M, Saba L, et al. Subtypes of constipation predominant irritable bowel syndrome based on rectal perception. Gut 1998;43:388-394.

36. Agrawal A, Houghton LA, Lea R, Morris J, Reilly B, Whorwell PJ. Bloating and distention in irritable bowel syndrome: the role of visceral sensation. Gastroenterology 2008;134:1882-1889.

37. Burgell RE, Bhan C, Lunniss PJ, Scott SM. Fecal incontinence in men: coexistent constipation and impact of rectal hyposensitivity. Dis Colon Rectum 2012;55:18-25.

38. Wijffels NA, Angelucci G, Ashrafi A, Jones OM, Cunningham C, Lindsey I. Rectal hyposensitivity is uncommon and unlikely to be the central cause of obstructed defecation in patients with highgrade internal rectal prolapse. Neurogastroenterol Motil 2011;23: 151-154. e30.

39. Carter D, Gabel MB. Rectocele-does the size matter? Int J Colorectal Dis 2012;27:975-980.

40. Voskuijl WP, van Ginkel R, Benninga MA, Hart GA, Taminiau JA, Boeckxstaens GE. New insight into rectal function in pediatric defecation disorders: disturbed rectal compliance is an essential mechanism in pediatric constipation. J Pediatr 2006;148:62-67.

41. Gosselink MJ, Schouten WR. Rectal sensory perception in females with obstructed defecation. Dis Colon Rectum 2001;44:1337-1344.

42. Burgell RE, Carrington EV, Mohammed S, Lunniss P, Scott SM. 
Quality of perception of the desire to defaecate and viscerosomatic referral patterns differ between patients with chronic constipation and healthy subjects. Neurogastroenterol Motil 2012 (In press)

43. Chan CL, Ponsford S, Scott SM, Swash M, Lunniss PJ. Contribution of the pudendal nerve to sensation of the distal rectum. Br J Surg 2005;92:859-865.

44. Brookes SJ, Dinning PG, Gladman MA. Neuroanatomy and physiology of colorectal function and defaecation: from basic science to human clinical studies. Neurogastroenterol Motil 2009;21(suppl 2):9-19.

45. Berthoud HR, Blackshaw LA, Brookes SJ, Grundy D. Neuroanatomy of extrinsic afferents supplying the gastrointestinal tract. Neurogastroenterol Motil 2004;16(suppl 1):28-33.

46. Knowles CH, Aziz Q. Basic and clinical aspects of gastrointestinal pain. Pain 2009;141:191-209.

47. Brock C, Arendt-Nielsen L, Wilder-Smith O, Drewes AM. Sensory testing of the human gastrointestinal tract. World J Gastroenterol 2009;15:151-159.

48. Kano M, Hamaguchi T, Itoh M, Yanai K, Fukudo S. Correlation between alexithymia and hypersensitivity to visceral stimulation in human. Pain 2007;132:252-263.

49. Arebi N, Gurmany S, Bullas D, Hobson A, Stagg A, Kamm M. Review article: the psychoneuroimmunology of irritable bowel syndrome - an exploration of interactions between psychological, neurological and immunological observations. Aliment Pharmacol Ther 2008;28:830-840.

50. Iovino P, Tremolaterra F, Boccia G, Miele E, Ruju FM, Staiano A. Irritable bowel syndrome in childhood: visceral hypersensitivity and psychosocial aspects. Neurogastroenterol Motil 2009;21:940e74.

51. Gladman MA, Dvorkin LS, Scott SM, Lunniss PJ, Williams NS. A novel technique to identify patients with megarectum. Dis Colon Rectum 2007;50:621-629.

52. Sun WM, Donnelly TC, Read NW. Utility of a combined test of anorectal manometry, electromyography, and sensation in determining the mechanism of 'idiopathic' faecal incontinence. Gut 1992; 33:807-813

53. Sun WM, Read NW, Donnelly TC. Anorectal function in incontinent patients with cerebrospinal disease. Gastroenterology 1990; 99:1372-1379.

54. Snooks SJ, Swash M, Henry MM, Setchell M. Risk factors in childbirth causing damage to the pelvic floor innervation. Int J Colorectal Dis 1986;1:20-24.

55. Lubowski DZ, Swash M, Nicholls RJ, Henry MM. Increase in pudendal nerve terminal motor latency with defaecation straining. Br J Surg 1988;75:1095-1097.

56. Scott SM, Lunniss PJ. Rectal hyposensitivity and functional hindgut disorders: cause and effect or an epiphenomenon? J Pediatr Gastroenterol Nutr 2011;53(suppl 2):S47-S49.

57. Remes-Troche JM, De-Ocampo S, Valestin J, Rao SS. Rectoanal reflexes and sensorimotor response in rectal hyposensitivity. Dis Colon Rectum 2010;53:1047-1054.

58. Hobson AR, Furlong PL, Sarkar S, et al. Neurophysiologic assessment of esophageal sensory processing in noncardiac chest pain. Gastroenterology 2006;130:80-88.

59. Paine P, Worthen SF, Gregory LJ, Thompson DG, Aziz Q.
Personality differences affect brainstem autonomic responses to visceral pain. Neurogastroenterol Motil 2009;21:1155-e98.

60. Coen SJ, Kano M, Farmer AD, et al. Neuroticism influences brain activity during the experience of visceral pain. Gastroenterology 2011;141:909-917. e1.

61. Sarkar S, Aziz Q, Woolf CJ, Hobson AR, Thompson DG. Contribution of central sensitisation to the development of non-cardiac chest pain. Lancet 2000;356:1154-1159.

62. Botha CA, Naqvi H, Chua YC, Knowles CH, Aziz Q. Effect of autonomic modulation on human esophageal pain hypersensitivity [abstract]. Gastroenterology 2011;140:S-164.

63. Burgell RE, Lelic D, Carrington EV, et al. Assessment of rectal afferent neuronal function and brain activity in patients with constipation and rectal hyposensitivity. Neurogastroenterol Motil 2012 (In press)

64. Drewes AM, Rössel P, Le Pera D, Arendt-Nielsen L, Valeriani M. Cortical neuroplastic changes to painful colon stimulation in patients with irritable bowel syndrome. Neurosci Lett 2005;375:157161.

65. Elsenbruch S, Rosenberger C, Enck P, Forsting M, Schedlowski $\mathrm{M}$, Gizewski ER. Affective disturbances modulate the neural processing of visceral pain stimuli in irritable bowel syndrome: an fMRI study. Gut 2010;59:489-495.

66. Altomare D, Pilot MA, Scott M, et al. Detection of subclinical autonomic neuropathy in constipated patients using a sweat test. Gut 1992;33:1539-1543.

67. Emmanuel AV, Kamm MA. Response to a behavioural treatment, biofeedback, in constipated patients is associated with improved gut transit and autonomic innervation. Gut 2001;49:214-219.

68. Raethjen J, Pilot MA, Knowles C, Warner G, Anand P, Williams $\mathrm{N}$. Selective autonomic and sensory deficits in slow transit constipation. J Auton Nerv Syst 1997;66:46-52.

69. Knowles CH, Scott SM, Wellmer A, et al. Sensory and autonomic neuropathy in patients with idiopathic slow-transit constipation. Br J Surg 1999;86:54-60.

70. Vasudevan SP, Scott SM, Gladman MA, Lunniss PJ. Rectal hyposensitivity: evaluation of anal sensation in female patients with refractory constipation with and without faecal incontinence. Neurogastroenterol Motil 2007;19:660-667.

71. Rao SS, Read NW, Davison PA, Bannister JJ, Holdsworth CD. Anorectal sensitivity and responses to rectal distention in patients with ulcerative colitis. Gastroenterology 1987;93:1270-1275.

72. Farthing MJ, Lennard-jones JE. Sensibility of the rectum to distension and the anorectal distension reflex in ulcerative colitis. Gut 1978;19:64-69.

73. Bernstein CN, Niazi N, Robert M, et al. Rectal afferent function in patients with inflammatory and functional intestinal disorders. Pain 1996;66:151-161.

74. Chang L, Munakata J, Mayer EA, et al. Perceptual responses in patients with inflammatory and functional bowel disease. Gut 2000; 47:497-505.

75. Dickhaus B, Mayer EA, Firooz N, et al. Irritable bowel syndrome patients show enhanced modulation of visceral perception by auditory stress. Am J Gastroenterol 2003;98:135-143.

76. Murray CD, Flynn J, Ratcliffe L, Jacyna MR, Kamm MA, Emmanuel AV. Effect of acute physical and psychological stress on 
gut autonomic innervation in irritable bowel syndrome. Gastroenterology 2004;127:1695-1703.

77. Drossman DA, Ringel Y, Vogt BA, et al. Alterations of brain activity associated with resolution of emotional distress and pain in a case of severe irritable bowel syndrome. Gastroenterology 2003;124: 754-761.

78. Ringel Y, Whitehead WE, Toner BB, et al. Sexual and physical abuse are not associated with rectal hypersensitivity in patients with irritable bowel syndrome. Gut 2004;53:838-842.

79. Guthrie E, Barlow J, Fernandes L, et al. Changes in tolerance to rectal distension correlate with changes in psychological state in patients with severe irritable bowel syndrome. Psychosom Med 2004; 66:578-582.

80. Annaházi A, Gecse K, Dabek M, et al. Fecal proteases from diarrheic-IBS and ulcerative colitis patients exert opposite effect on visceral sensitivity in mice. Pain 2009;144:209-217.

81. Bharucha AE, Wald A, Enck P, Rao S. Functional anorectal disorders. Gastroenterology 2006;130:1510-1518.

82. Schouten WR, Gosselink MJ, Boerma MO, Ginai AZ. Rectal wall contractility in response to an evoked urge to defecate in patients with obstructed defecation. Dis Colon Rectum 1998;41:473-479.

83. Metcalf AM, Phillips SF, Zinsmeister AR, MacCarty RL, Beart RW, Wolff BG. Simplified assessment of segmental colonic transit. Gastroenterology 1987;92:40-47.

84. Mollen RM, Salvioli B, Camilleri M, et al. The effects of biofeedback on rectal sensation and distal colonic motility in patients with disorders of rectal evacuation: evidence of an inhibitory rectocolonic reflex in humans? Am J Gastroenterology 1999;94:751-756.

85. Gladman MA, Lunniss PJ, Scott SM, Swash M. Rectal hyposensitivity. Am J Gastroenterology 2006;101:1140-1151.

86. Kellow JE, Gill RC, Wingate DL. Modulation of human upper gastrointestinal motility by rectal distension. Gut 1987;28:864-868.

87. Nurko S, Scott SM. Coexistence of constipation and incontinence in children and adults. Best Pract Res Clin Gastroenterol 2011; 25:29-41.

88. Kang HW, Jung HK, Kwon KJ, et al. Prevalence and predictive factors of fecal incontinence. J Neurogastroenterol Motil 2012;18: 86-93.

89. Madoff RD, Parker SC, Varma MG, Lowry AC. Faecal incontinence in adults. Lancet 2004;364:621-632.

90. Read NW, Abouzekry L. Why do patients with faecal impaction have faecal incontinence. Gut 1986;27:283-287.

91. Sun WM, Read NW, Miner PB. Relation between rectal sensation and anal function in normal subjects and patients with faecal incontinence. Gut 1990;31:1056-1061.

92. Schnelle JF, Leung FW, Rao SSC, et al. A controlled trial of an intervention to improve urinary and fecal incontinence and constipation. J Am Geriatr Soc 2010;58:1504-1511.

93. Bhan C, Prosser K, Gill KA, et al. Prospective randomized double blind placebo-controlled crossover study of sacral nerve stimulation in patients with severe evacuatory dysfunction allied to rectal hyposensitivity [abstract]. Neurogastroenterol Motil 2009;21:12.

94. Lee KJ, Kim JH, Cho SW. Short-term effects of magnetic sacral dermatome stimulation for idiopathic slow transit constipation: sham-controlled, cross-over pilot study. J Gastroenterol Hepatol 2006;21(1 Pt 1):47-53.
95. Williams NS, Fajobi OA, Lunniss PJ, Scott SM, Eccersley AJ, Ogunbiyi OA. Vertical reduction rectoplasty: a new treatment for idiopathic megarectum. Br J Surg 2000;87:1203-1208.

96. Rao SS, Welcher KD, Pelsang RE. Effects of biofeedback therapy on anorectal function in obstructive defecation. Dig Dis Sci 1997; 42:2197-2205.

97. Peticca L, Pescatori M. Outlet obstruction due to anismus and rectal hyposensation: effect of biofeedback training. Colorectal Dis 2002;4:67.

98. Rao SS. Biofeedback therapy for constipation in adults. Best Pract Clin Gastroenterol 2011;25:159-166.

99. Chiarioni G, Bassotti G, Stanganini S, Vantini I, Whitehead WE. Sensory retraining is key to biofeedback therapy for formed stool fecal incontinence. Am J Gastroenterol 2002;97:109-117.

100. Wald A, Tunuguntla AK. Anorectal sensorimotor dysfunction in fecal incontinence and diabetes mellitus. Modification with biofeedback therapy. N Engl J Med 1984;310:1282-1287.

101. Ozturk R, Niazi S, Stessman M, Rao SS. Long-term outcome and objective changes of anorectal function after biofeedback therapy for faecal incontinence. Aliment Pharmacol Ther 2004;20:667-674.

102. Bharucha AE, Edge J, Zinsmeister AR. Effect of nifedipine on anorectal sensorimotor functions in health and fecal incontinence. Am J Physiol Gastrointest Liver Physiol 2011;301:G175-G180.

103. Bharucha AE, Seide BM, Zinsmeister AR. The effects of clonidine on symptoms and anorectal sensorimotor function in women with faecal incontinence. Aliment Pharmacol Ther 2010;32:681-688.

104. Bharucha AE, Camilleri M, Zinsmeister AR, Hanson RB. Adrenergic modulation of human colonic motor and sensory function. Am J Physiol 1997;273(5 Pt 1):G997-G1006.

105. Bharucha AE, Camilleri M, Haydock S, et al. Effects of a serotonin 5-HT(4) receptor antagonist SB-207266 on gastrointestinal motor and sensory function in humans. Gut 2000;47:667-674.

106. Milone M, DiBaise JK. A pilot study of the effects of sildenafil on stool characteristics, colon transit, anal sphincter function, and rectal sensation in healthy men. Dig Dis Sci 2005;50:1005-1011.

107. Mowatt G, Glazener C, Jarrett M. Sacral nerve stimulation for faecal incontinence and constipation in adults. Cochrane Database Syst Rev 2007;(3):CD004464.

108. Carrington EV, Knowles CH. The influence of sacral nerve stimulation on anorectal dysfunction. Colorectal Dis 2011;13(suppl 2):5-9.

109. Hetzer FH, Bieler A, Hahnloser D, Löhlein F, Clavien PA, Demartines $\mathrm{N}$. Outcome and cost analysis of sacral nerve stimulation for faecal incontinence. Br J Surg 2006;93:1411-1417.

110. Jarrett ME, Mowatt G, Glazener CM, et al. Systematic review of sacral nerve stimulation for faecal incontinence and constipation. $\mathrm{Br}$ J Surg 2004;91:1559-1569.

111. Kenefick NJ, Vaizey CJ, Cohen CRG, Nicholls RJ, Kamm MA. Double-blind placebo-controlled crossover study of sacral nerve stimulation for idiopathic constipation. Br J Surg 2002;89:15701571.

112. Kamm MA, Dudding TC, Melenhorst J, et al. Sacral nerve stimulation for intractable constipation. Gut 2010;59:333-340.

113. Knowles $\mathrm{CH}$, Thin $\mathrm{N}$, Gill $\mathrm{K}$, et al. Prospective randomized double-blind study of temporary sacral nerve stimulation in patients with rectal evacuatory dysfunction and rectal hyposensitivity. Ann 
Surg 2012;25 5:643-649.

114. Uludag O, Morren GL, Dejong CH, Baeten CG. Effect of sacral neuromodulation on the rectum. Br J Surg 2005;92:1017-1023.

115. Michelsen HB, Buntzen S, Krogh K, Laurberg S. Rectal volume tolerability and anal pressures in patients with fecal incontinence treated with sacral nerve stimulation. Dis Colon Rectum 2006;49: 1039-1044.

116. Altomare DF, Ratto C, Ganio E, Lolli P, Masin A, Villani RD. Long-term outcome of sacral nerve stimulation for fecal incontinence. Dis Colon Rectum 2009;52:11-17.

117. Jarrett ME, Varma JS, Duthie GS, Nicholls RJ, Kamm MA. Sacral nerve stimulation for faecal incontinence in the UK. Br J Surg 2004; 91:755-761.

118. Kenefick NJ. Sacral nerve neuromodulation for the treatment of lower bowel motility disorders. Ann R Coll Surg Engl 2006;88:617623.

119. Chang HS, Myung SJ, Yang SK, et al. Functional constipation with impaired rectal sensation improved by electrical stimulation therapy: report of a case. Dis Colon Rectum 2004;47:933-936.

120. Chang HS, Myung SJ, Yang SK, et al. Effect of electrical stimulation in constipated patients with impaired rectal sensation. Int J Colorectal Dis 2003;18:433-438.

121. Leong LC, Yik YI, Catto-Smith AG, Robertson VJ, Hutson JM, Southwell BR. Long-term effects of transabdominal electrical stimulation in treating children with slow-transit constipation. J Pediatr Surg 2011;46:2309-2312.

122. Worsøe J, Fynne L, Laurberg S, Krogh K, Rijkhoff NJM. Acute effect of electrical stimulation of the dorsal genital nerve on rectal ca- pacity in patients with spinal cord injury. Spinal Cord 201;50:462466.

123. Chiu CM, Wang CP, Sung WH, Huang SF, Chiang SC, Tsai PY. Functional magnetic stimulation in constipation associated with Parkinson's disease. J Rehabil Med 2009;41:1085-1089.

124. Tsai PY, Wang CP, Chiu FY, Tsai YA, Chang YC, Chuang TY. Efficacy of functional magnetic stimulation in neurogenic bowel dysfunction after spinal cord injury. J Rehabil Med 2009;41:41-47.

125. Morren GL, Walter S, Hallböök O, Sjödahl R. Effects of magnetic sacral root stimulation on anorectal pressure and volume. Dis Colon Rectum 2001;44:1827-1833.

126. Gladman MA, Knowles CH. Surgical treatment of patients with constipation and fecal incontinence. Gastroenterol Clin North Am 2008;37:605-625. vii.

127. Knowles CH, Dinning PG, Pescatori M, Rintala R, Rosen H. Surgical management of constipation. Neurogastroenterol Motil 2009;21(suppl 2):62-71.

128. Gladman MA, Williams NS, Scott SM, Ogunbiyi OA, Lunniss PJ. Medium-term results of vertical reduction rectoplasty and sigmoid colectomy for idiopathic megarectum. Br J Surg 2005;92: 624-630.

129. Pijpers MA, Bongers ME, Benninga MA, Berger MY. Functional constipation in children: a systematic review on prognosis and predictive factors. J Pediatr Gastroenterol Nutr 2010;50:256-268.

130. Staiano A, Andreotti MR, Greco L, Basile P, Auricchio S. Longterm follow-up of children with chronic idiopathic constipation. Dig Dis Sci 1994;39:561-564. 